Supporting Information For:

\title{
Self-Assembling Behavior and Chiroptical Properties of Carbazole-Cored Phenyl Isoxazolyl Benzenes
}

Yudai Ono, ${ }^{\mathrm{a}, \dagger}$ Takehiro Hirao, ${ }^{\mathrm{b}, \dagger}{ }^{\dagger}$ Toshiaki Ikeda ${ }^{\mathrm{c}}$ and Takeharu Haino*b

${ }^{a}$ Department of Chemistry, Graduate School of Science, Hiroshima University, 1-3-1 Kagamiyama, Higashi-Hiroshima, Hiroshima, 739-8526, JAPAN

${ }^{b}$ Department of Chemistry, Graduate School of Advanced Science and Engineering, Hiroshima University, 1-3-1

Kagamiyama, Higashi-Hiroshima, Hiroshima, 739-8526, JAPAN

'Department of Chemistry, Faculty of Science, Tokai University, 4-1-1 Kitakaname, Hiratsuka, Kanazawa, 259-1292, JAPAN

To whom correspondence should be addressed: *Email: haino@hiroshima-u.ac.jp

†These authors contributed equally to this work. 


\section{Contents}

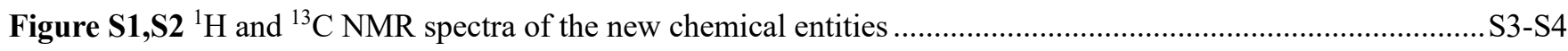

Figure S3,S4 Concentration-dependent ${ }^{1} \mathrm{H}$ NMR spectra of $(S)$ - and $(R)-1$ in chloroform- $d$................................S5-S6

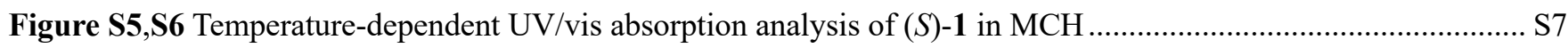

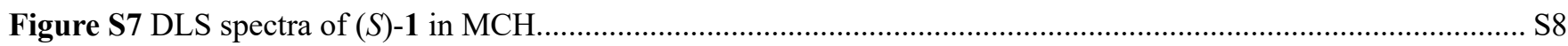

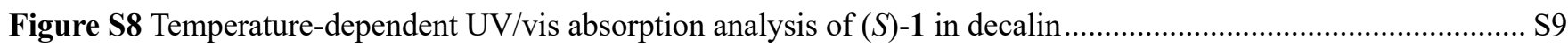

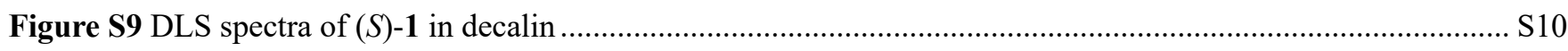

Figure S10 Temperature-dependent UV/vis absorption analysis of $(S)-\mathbf{1}$ in cis- and trans-decalin ........................... S11

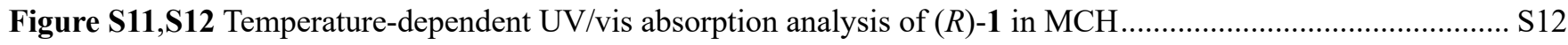

Figure S13 Temperature-dependent UV/vis absorption analysis of $(R)-\mathbf{1}$ in cis- and trans-decalin.......................... S13

Figure S14 Temperature-dependent UV/vis absorption analysis of $(R)-\mathbf{1}$ in decalin ............................................ S14

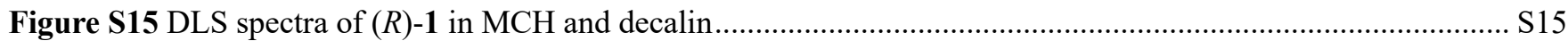

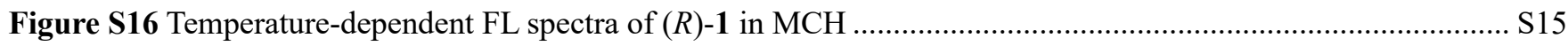

Figure S17 Temperature-dependent FL $((S)-1)$ and CPL $((S)$ - and $(R)-1)$ spectra in decalin .................................. S16

Figure S18 Temperature-dependent FL spectra of $(R)-1$ in decalin....................................................................... S16

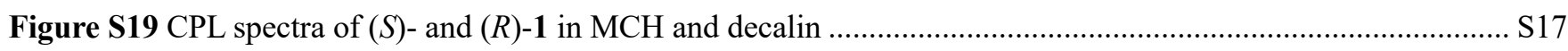

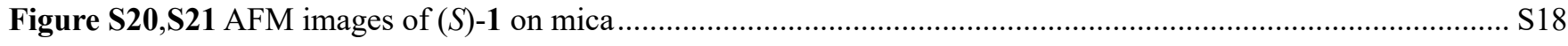

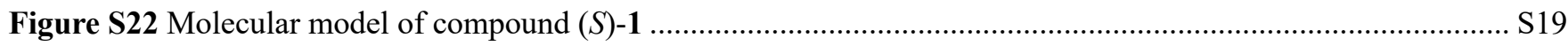

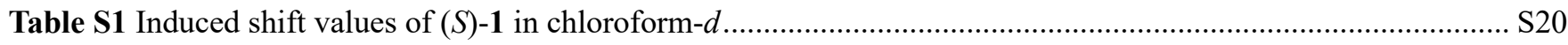

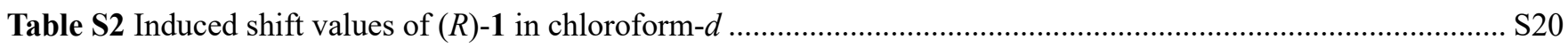

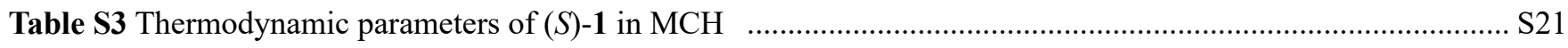

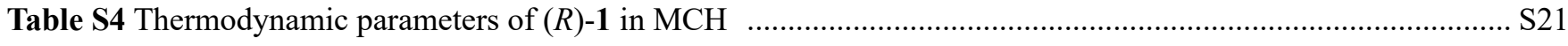

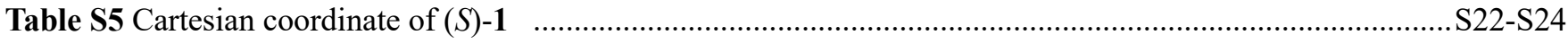



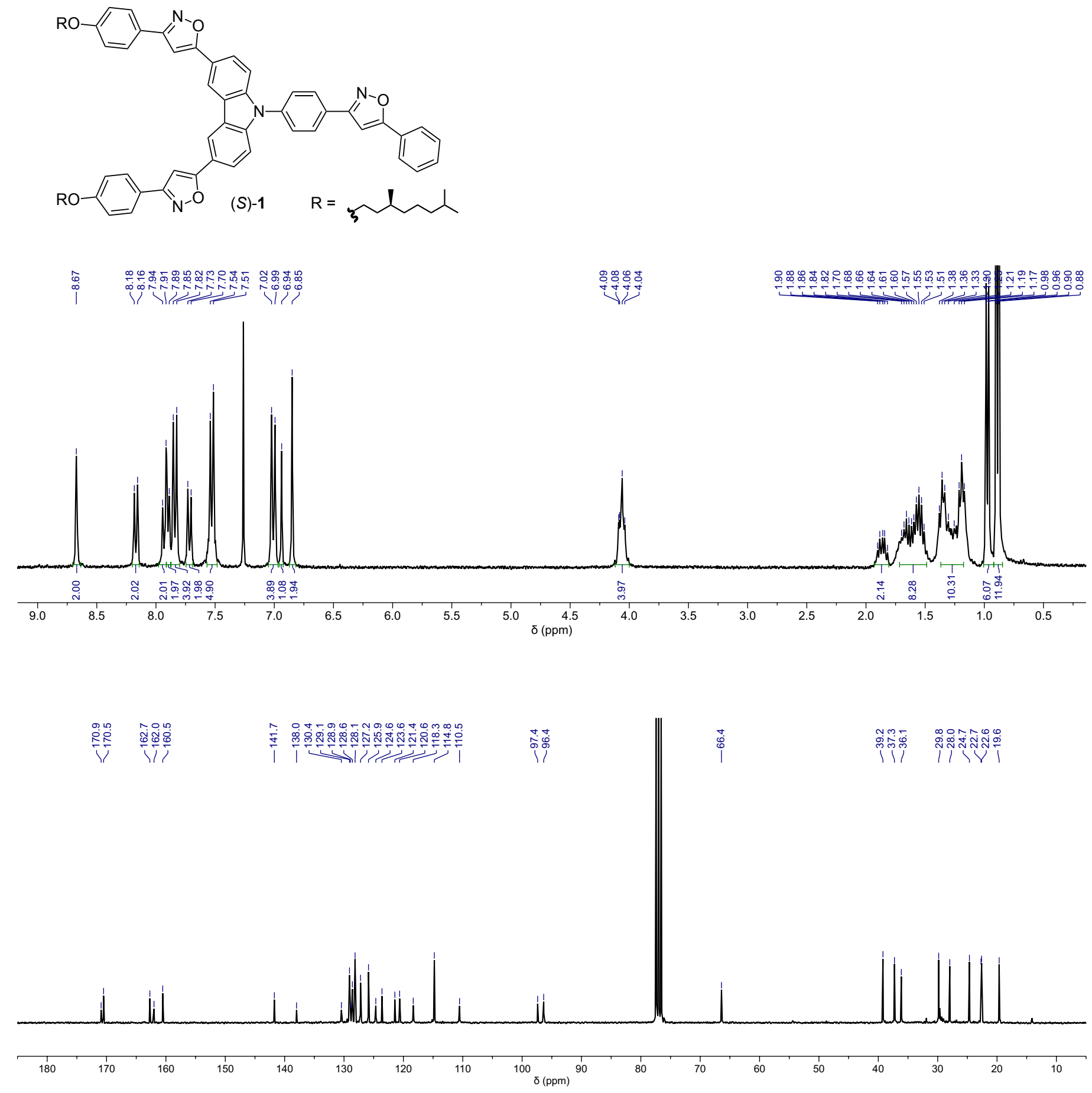

Figure S1. ${ }^{1} \mathrm{H}(300 \mathrm{MHz})$ and ${ }^{13} \mathrm{C}\left\{{ }^{1} \mathrm{H}\right\}$ NMR $(75 \mathrm{MHz})$ spectra of $(S)-\mathbf{1}$ in chloroform- $d$. 

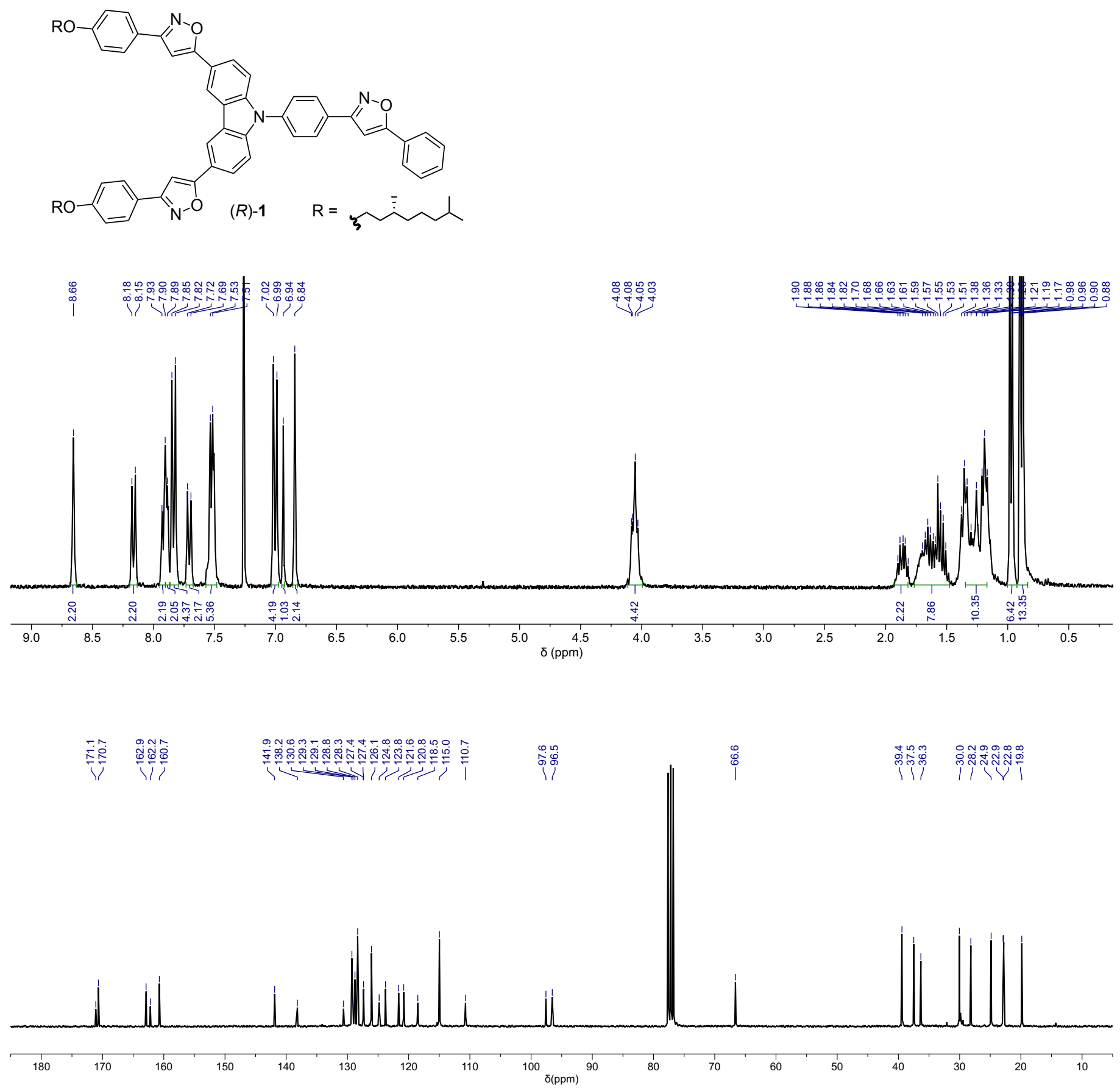

Figure S2. ${ }^{1} \mathrm{H}(300 \mathrm{MHz})$ and ${ }^{13} \mathrm{C}\left\{{ }^{1} \mathrm{H}\right\}$ NMR $(75 \mathrm{MHz})$ spectra of $(R)-\mathbf{1}$ in chloroform- $d$. 

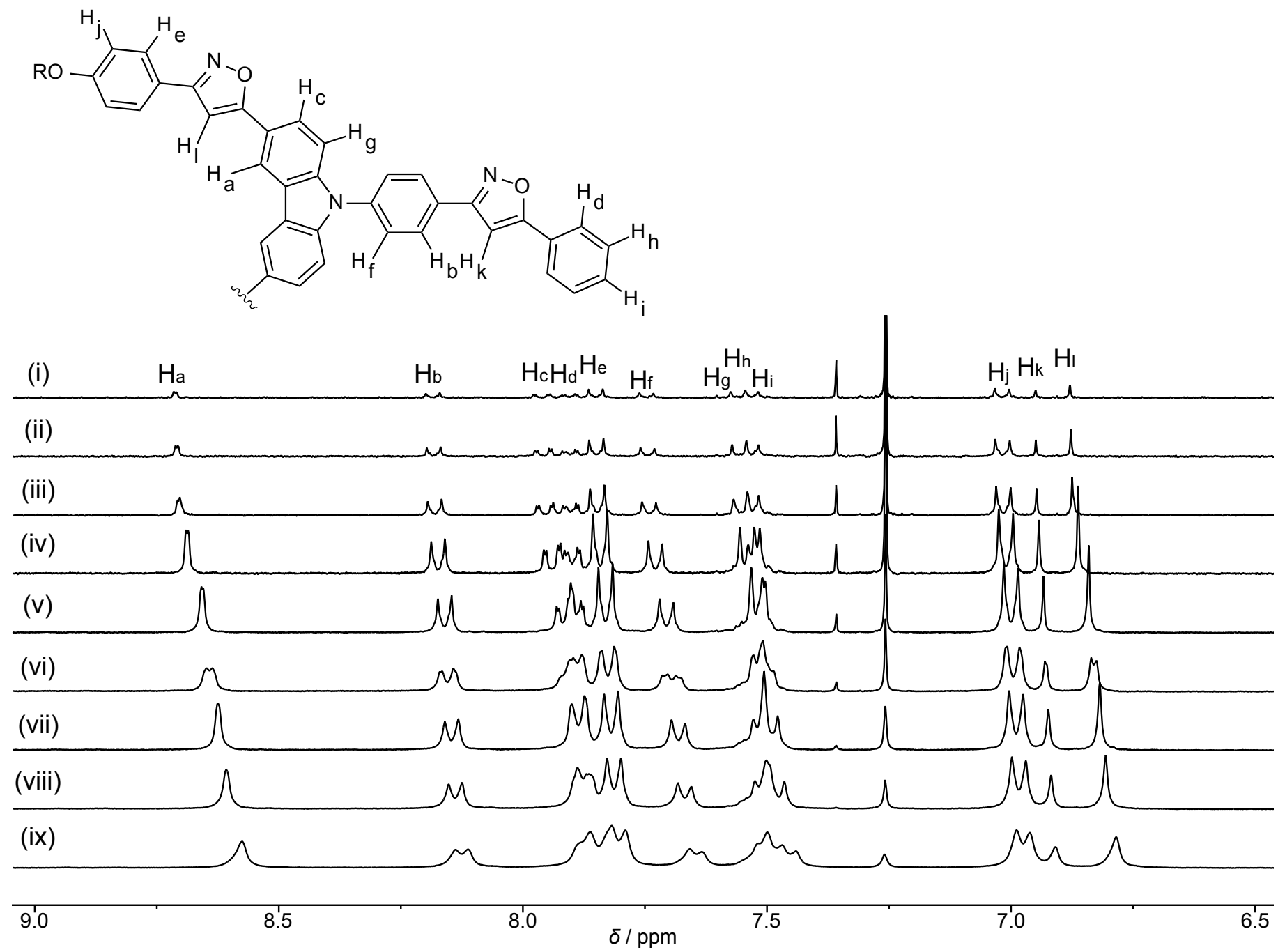

Figure S3. Concentration-dependent ${ }^{1} \mathrm{H}$ NMR spectra of $(S)-1$ in chloroform- $d$ at $25{ }^{\circ} \mathrm{C}$. The concentrations are (i) 0.5 , (ii) 1.0, (iii) 2.0, (iv) 5.0, (v) 10.0, (vi) 15.0, (vii) 20.0, (viii) 25.0 and (xi) $30.0 \mathrm{mmol} \mathrm{L}^{-1}$. 


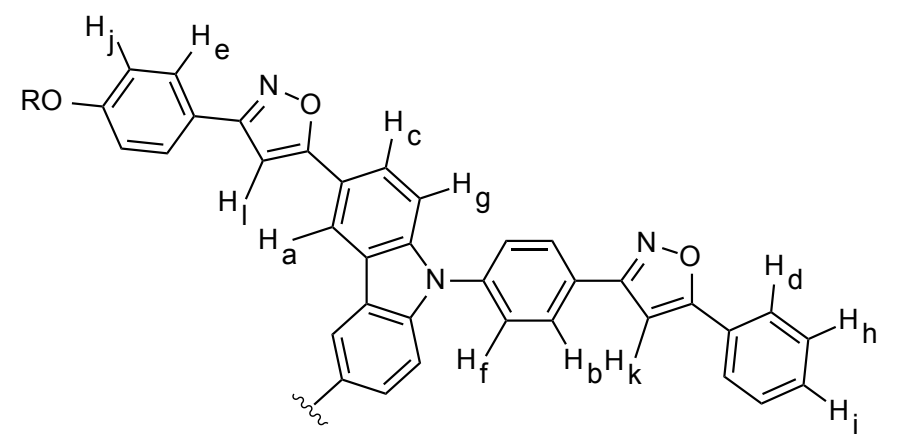

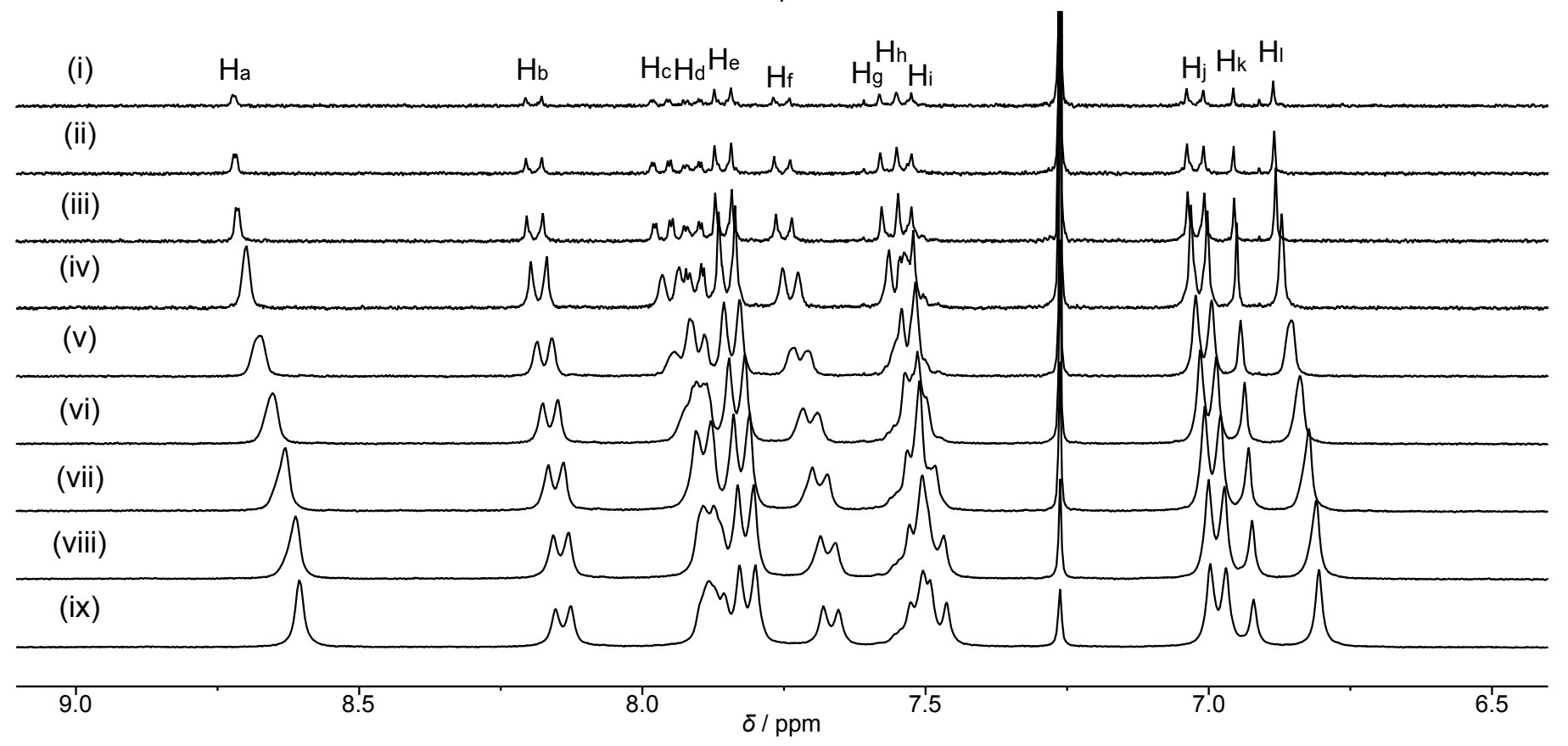

Figure S4. Concentration-dependent ${ }^{1} \mathrm{H}$ NMR spectra of $(R)-1$ in chloroform- $d$ at $25^{\circ} \mathrm{C}$. The concentrations are (i) 0.5 , (ii) 1.0, (iii) 2.0, (iv) 5.0, (v) 10.0, (vi) 15.0, (vii) 20.0, (viii) 25.0 and (xi) $30.0 \mathrm{mmol} \mathrm{L}^{-1}$. 
(a)

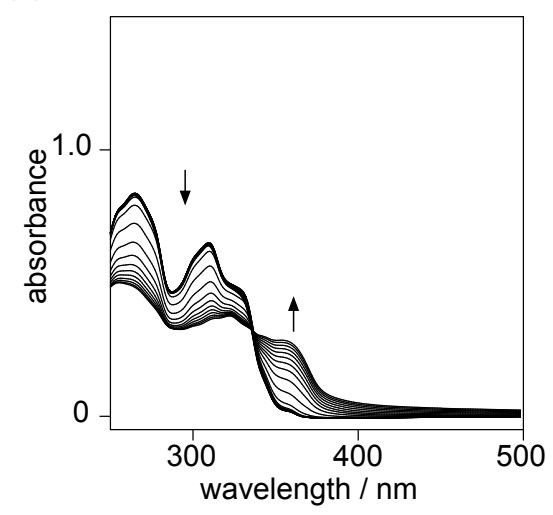

(c)

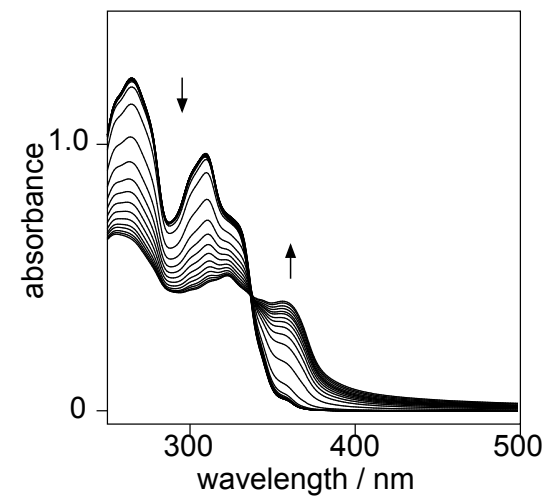

(b)

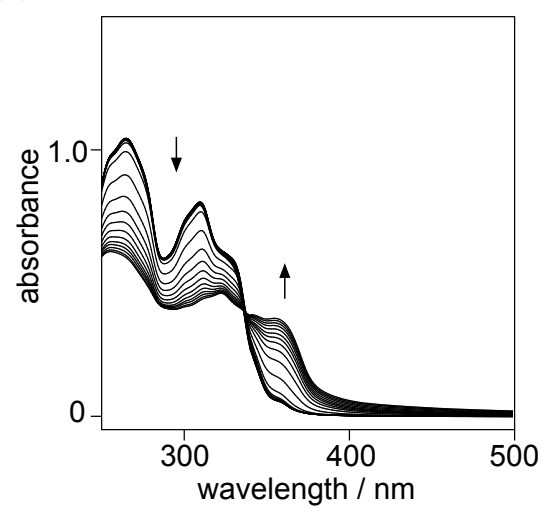

(d)

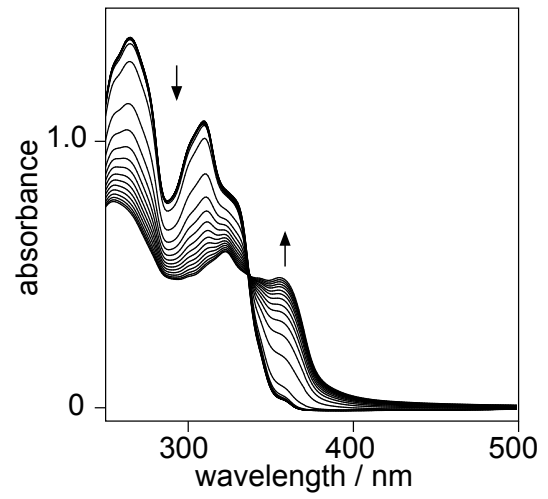

Figure S5. Temperature-dependent UV/vis absorption spectra of $(S)-\mathbf{1}$ in $\mathrm{MCH}$ at various concentrations. Concentrations are (a) 3.0, (b) 3.5 (c) 4.0 and (d) $5.0 \times 10^{-5} \mathrm{~mol} \mathrm{~L}-1$. Recorded from $50{ }^{\circ} \mathrm{C}$ to $0{ }^{\circ} \mathrm{C}$ and the cooling rate is $1{ }^{\circ} \mathrm{C} / \mathrm{min}$.

(a)

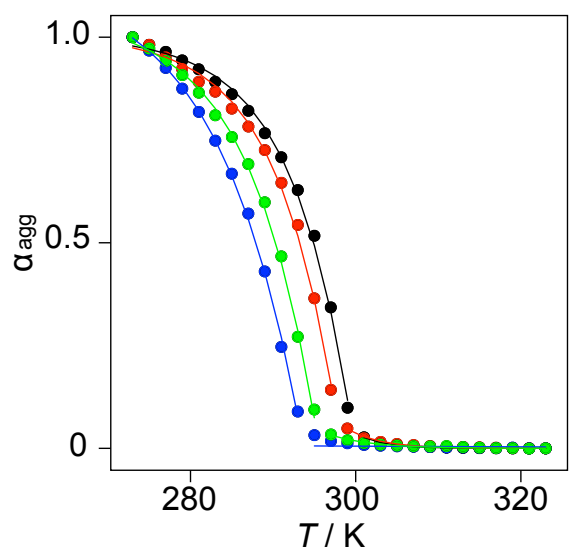

(b)

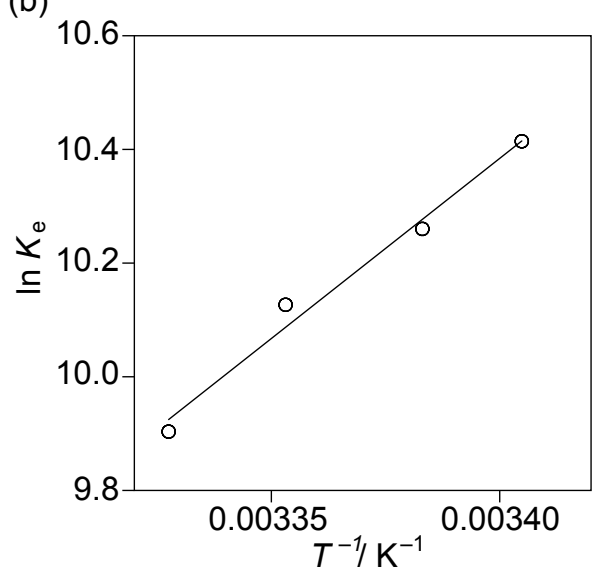

Figure S6. (a) Plot of the degree of aggregation $\left(\alpha_{\mathrm{agg}}\right)$ of $(S)-\mathbf{1}$ in $\mathrm{MCH}$ at $360 \mathrm{~nm}$ as a function of temperature at various concentrations. Concentrations are (black) 5.0, (red) 4.0, (green) 3.5 and (blue) $3.0 \times 10^{-5} \mathrm{~mol} \mathrm{~L}^{-1}$. Solid lines exhibit the fitting curve. (b) Van' t Hoff plot of $\ln \left(K_{\mathrm{e}}\right)$ vs $T^{-1}$ for the compound (S)-1. 


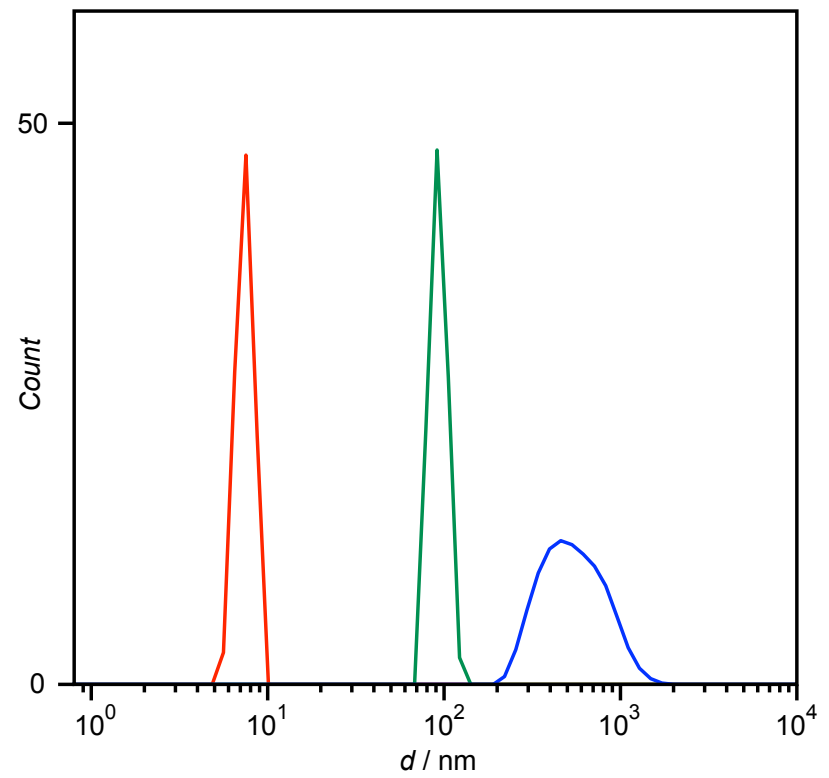

Figure S7. Hydrodynamic diameters seen in the $\mathrm{MCH}$ solution of $(S)-1$ at (red) $50{ }^{\circ} \mathrm{C}$, (green) $27^{\circ} \mathrm{C}$, and (blue) $2{ }^{\circ} \mathrm{C}$, as inferred from dynamic light scattering experiments. 
(a)

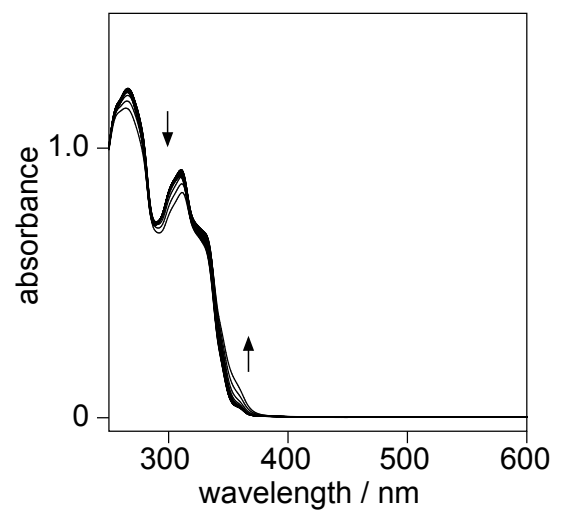

(c)

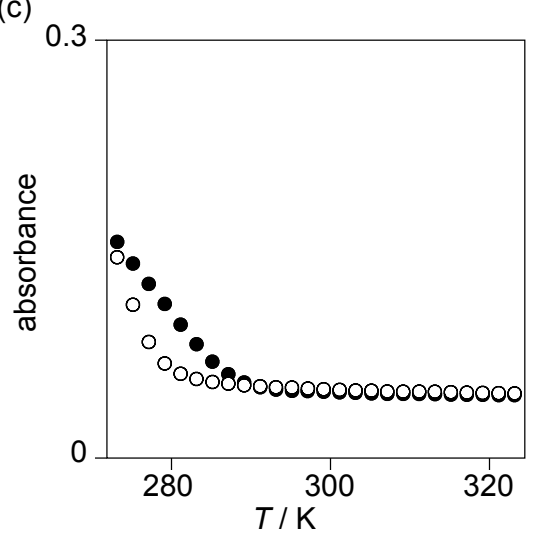

(b)

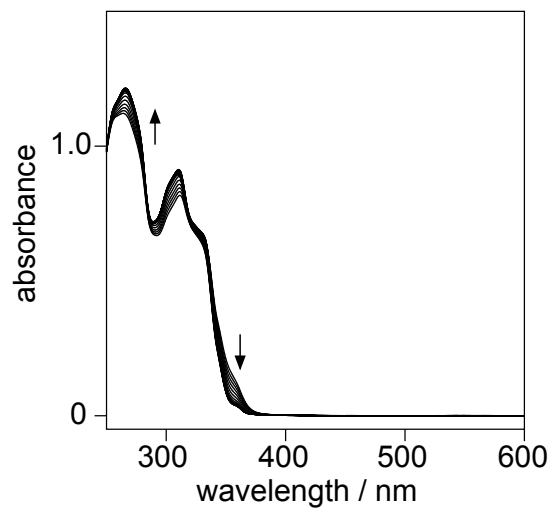

Figure S8. Temperature-dependent UV/vis spectra of $(S)-\mathbf{1}$ in decalin (cis, trans mixture). The spectra were recorded from (a) $50{ }^{\circ} \mathrm{C}$ to $0^{\circ} \mathrm{C}$ and from (b) $0{ }^{\circ} \mathrm{C}$ to $50^{\circ} \mathrm{C}$. The cooling and heating rate are $1{ }^{\circ} \mathrm{C} / \mathrm{min}$. $[(S)-1]=5.0 \times 10^{-5} \mathrm{~mol} \mathrm{~L} \mathrm{~L}^{-1}$. (c) The plot of absorbance at $355 \mathrm{~nm}$ in decalin. The cooling (open circle) and heating process (closed circle) gave weak hysteresis. 


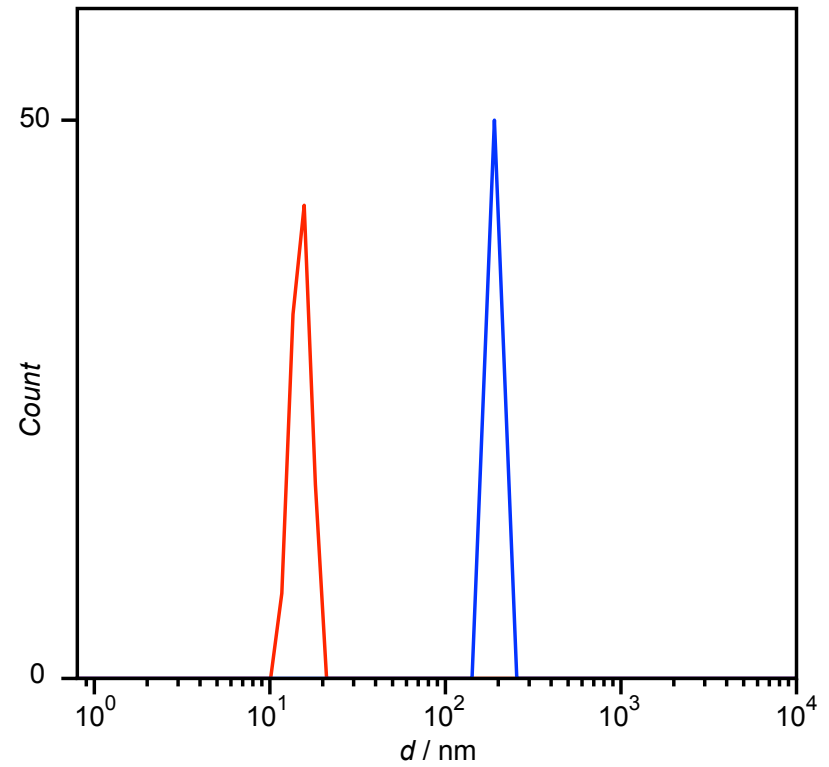

Figure S9. Hydrodynamic diameters seen in the decalin solution of $(S)-1$ at (red) $50{ }^{\circ} \mathrm{C}$ and (blue) $2{ }^{\circ} \mathrm{C}$, as inferred from dynamic light scattering experiments. 

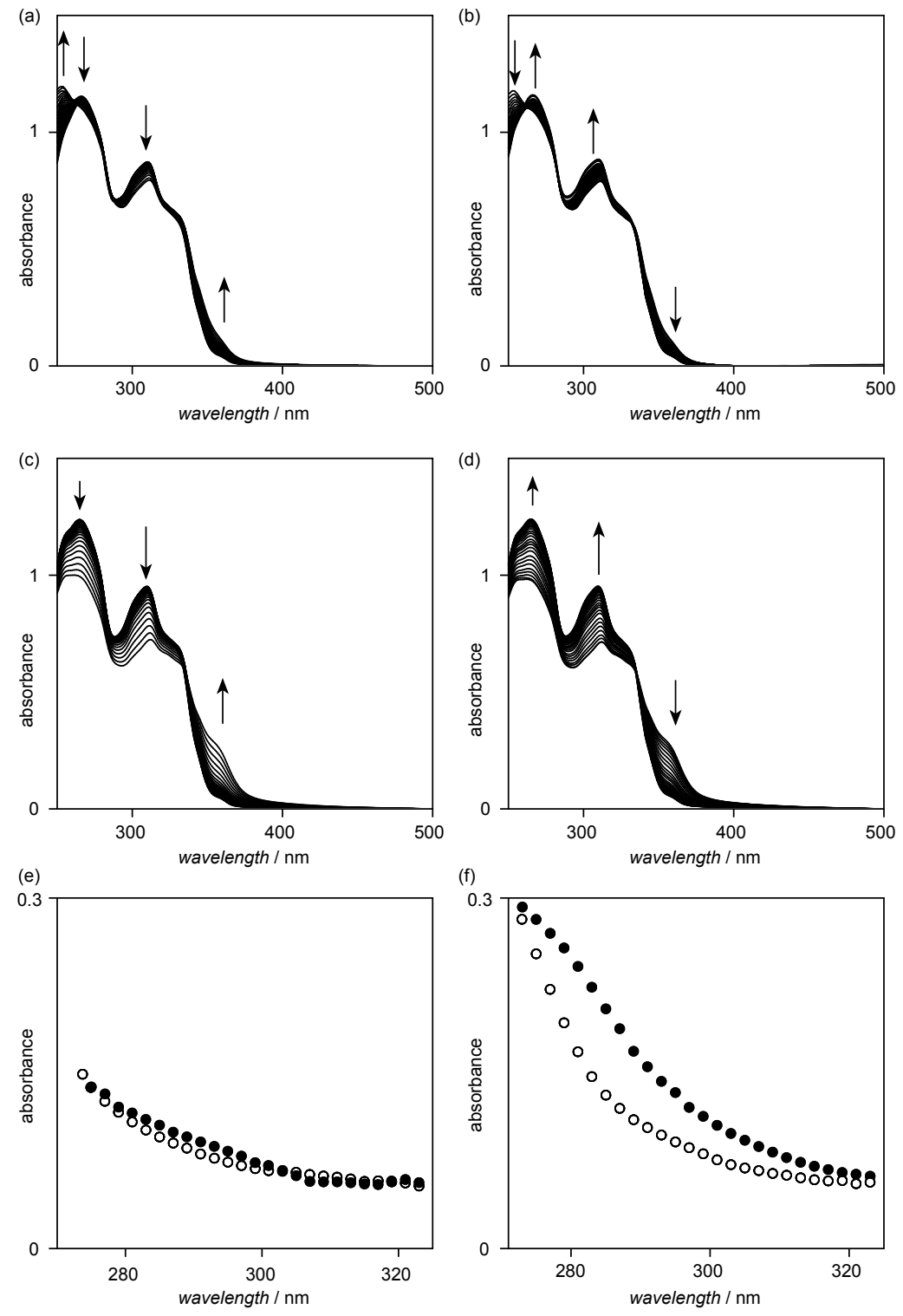

Figure S10. Temperature-dependent UV/vis spectra of $(S)-\mathbf{1}$ in isomerically pure $(a, b)$ cis- and $(c, d)$ trans-decalin. The spectra were recorded from $(\mathrm{a}, \mathrm{b}) 50{ }^{\circ} \mathrm{C}$ to $0{ }^{\circ} \mathrm{C}$ and from $(\mathrm{c}, \mathrm{d}) 0{ }^{\circ} \mathrm{C}$ to $50{ }^{\circ} \mathrm{C}$. The cooling and heating rate are $1{ }^{\circ} \mathrm{C} / \mathrm{min}$. $[(S)-1]=$ $5.0 \times 10^{-5} \mathrm{~mol} \mathrm{~L}^{-1}$. The plot of absorbance at $355 \mathrm{~nm}$ in (e) cis- and (f) trans-decalin. The cooling (open circle) and heating process (closed circle) gave weak hysteresis. 

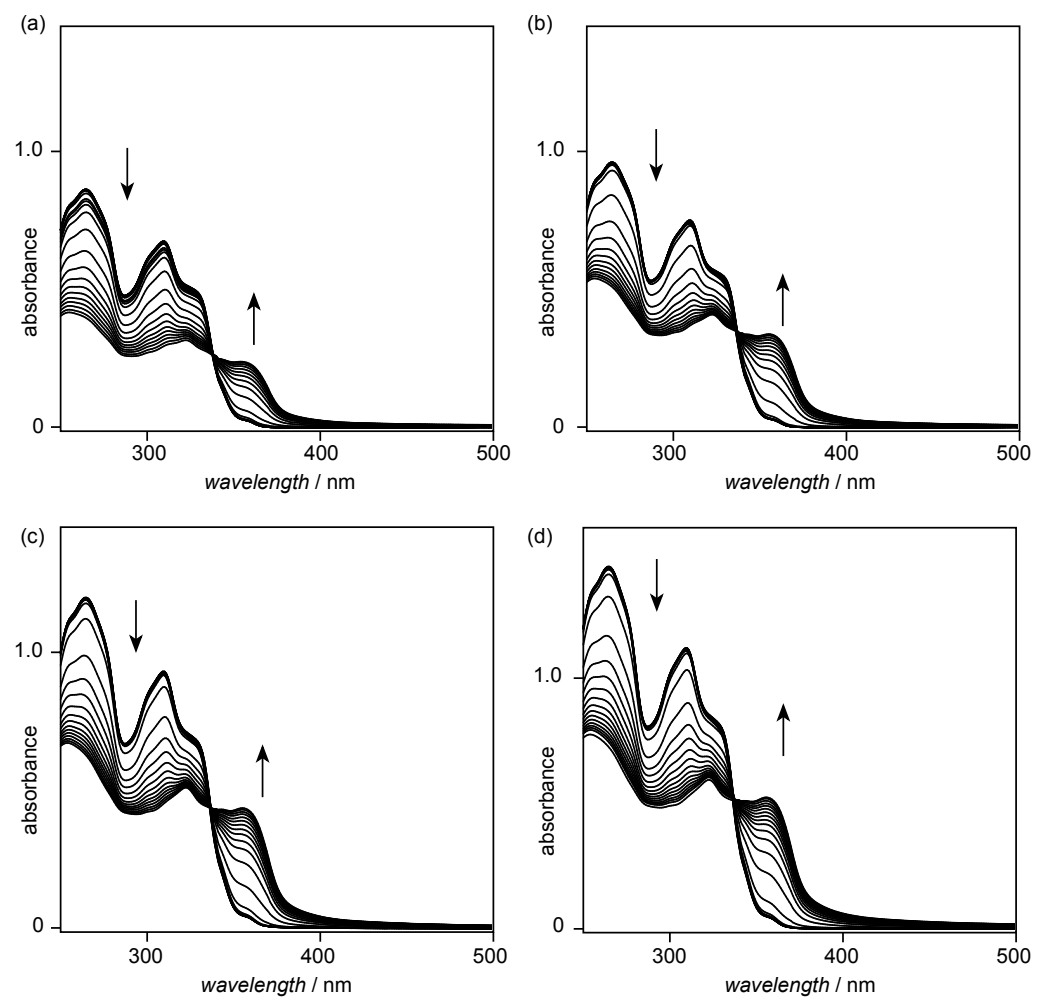

Figure S11. Temperature-dependent UV/vis absorption spectra of $(R)-\mathbf{1}$ in $\mathrm{MCH}$ at various concentrations. Concentrations are (a) 3.0, (b) 3.5 (c) 4.0 and (d) $5.0 \times 10^{-5} \mathrm{~mol} \mathrm{~L}-1$. Recorded from $50{ }^{\circ} \mathrm{C}$ to $0{ }^{\circ} \mathrm{C}$ and the cooling rate is $1{ }^{\circ} \mathrm{C} / \mathrm{min}$.

(a)

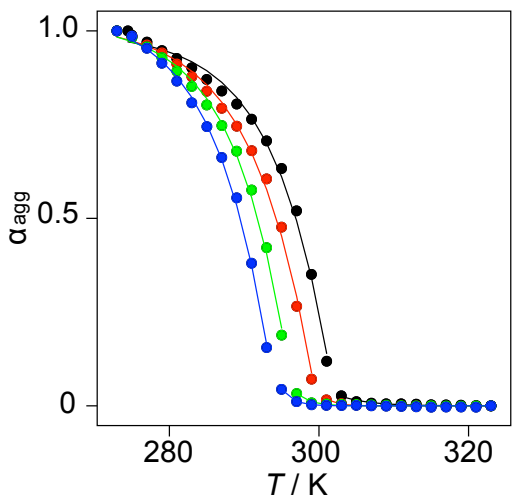

(b)

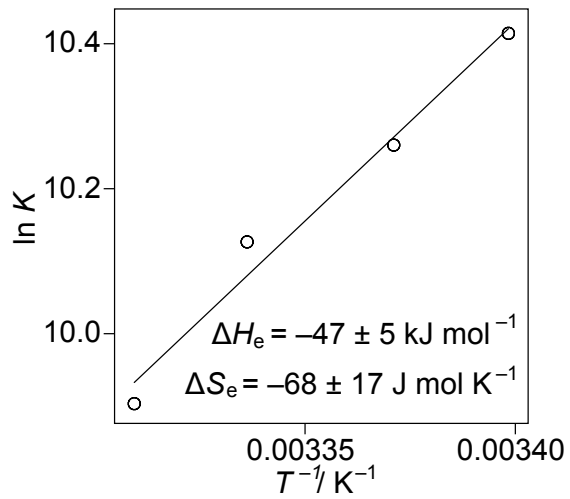

Figure S12. (a) Plot of the degree of aggregation $\left(\alpha_{\mathrm{agg}}\right)$ of $(R)-1$ in $\mathrm{MCH}$ at $360 \mathrm{~nm}$ as a function of temperature at various concentrations. Concentrations are (black) 5.0, (red) 4.0, (green) 3.5 and (blue) $3.0 \times 10^{-5} \mathrm{~mol} \mathrm{~L}^{-1}$. Solid lines exhibit the fitting curve. (b) Van' t Hoff plot of $\ln \left(K_{\mathrm{e}}\right)$ vs $T^{-1}$ for the compound $(R)-1$. 

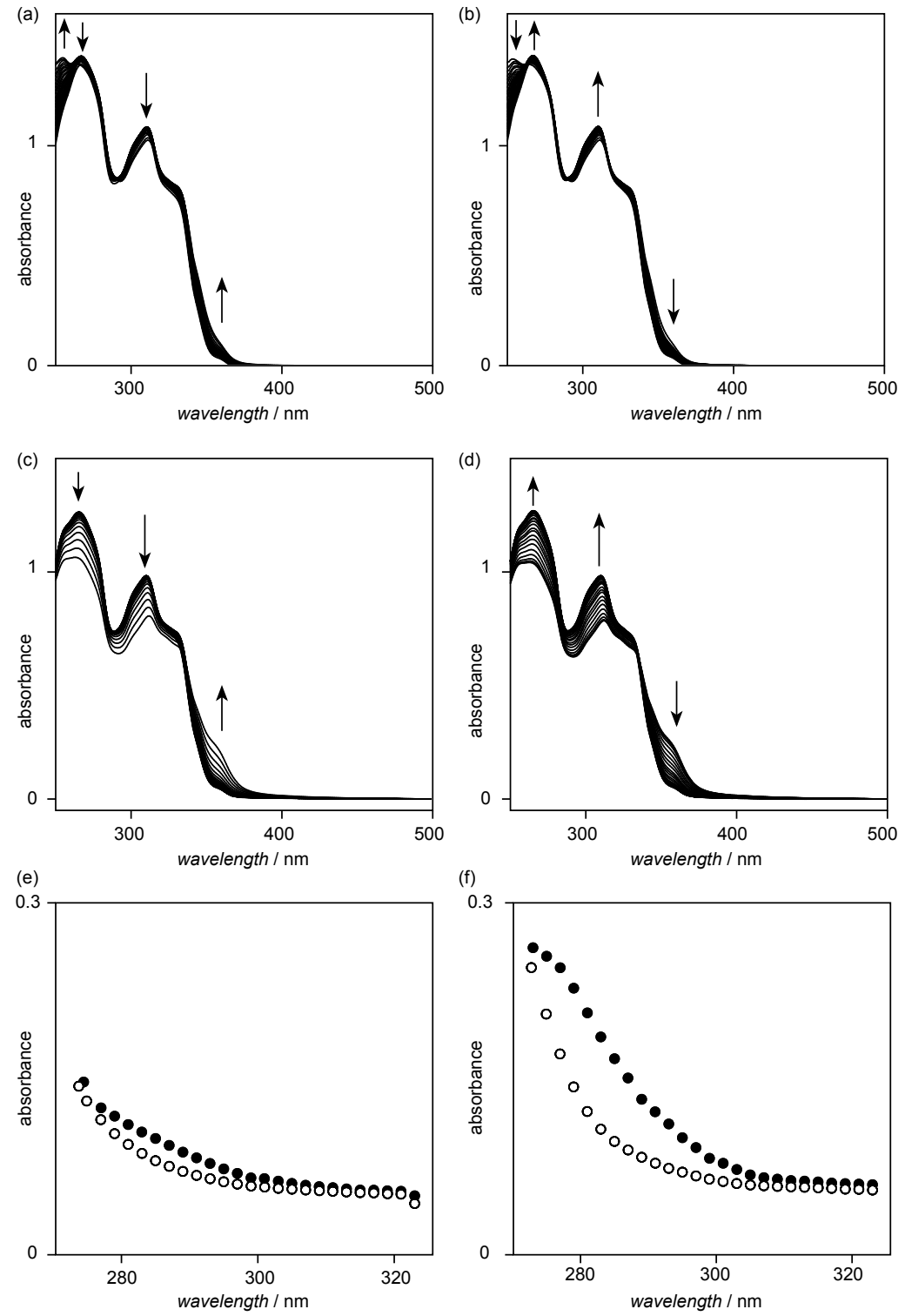

Figure S13. Temperature-dependent UV/vis spectra of $(R)-\mathbf{1}$ in isomerically pure (a,b) cis- and (c,d) trans-decalin. The spectra were recorded from $(\mathrm{a}, \mathrm{b}) 50{ }^{\circ} \mathrm{C}$ to $0{ }^{\circ} \mathrm{C}$ and from $(\mathrm{c}, \mathrm{d}) 0{ }^{\circ} \mathrm{C}$ to $50{ }^{\circ} \mathrm{C}$. The cooling and heating rate are $1{ }^{\circ} \mathrm{C} / \mathrm{min}$. $[(R)-1]=$ $5.0 \times 10^{-5} \mathrm{~mol} \mathrm{~L}^{-1}$. The plot of absorbance at $355 \mathrm{~nm}$ in (e) cis- and (f) trans-decalin. The cooling (open circle) and heating process (closed circle) gave weak hysteresis. 

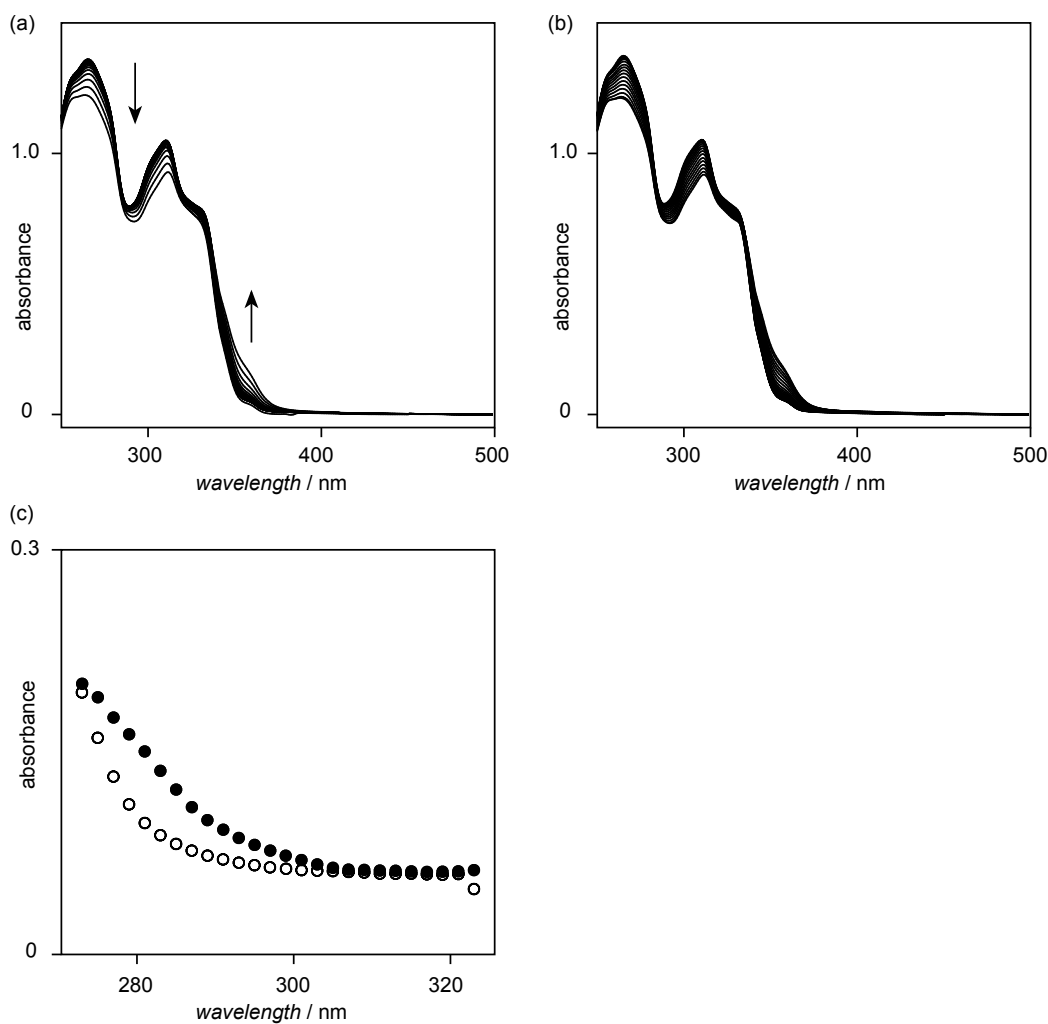

Figure S14. Temperature-dependent UV/vis spectra of $(R)-\mathbf{1}$ in decalin (cis, trans mixture). The spectra were recorded from (a) $50{ }^{\circ} \mathrm{C}$ to $0{ }^{\circ} \mathrm{C}$ and from (b) $0{ }^{\circ} \mathrm{C}$ to $50{ }^{\circ} \mathrm{C}$. The cooling and heating rate are $1{ }^{\circ} \mathrm{C} / \mathrm{min}$. $[(R)-1]=5.0 \times 10^{-5} \mathrm{~mol} \mathrm{~L}^{-1}$. (c) The plot of absorbance at $355 \mathrm{~nm}$ in decalin. The cooling (open circle) and heating process (closed circle) gave weak hysteresis. 
(a)

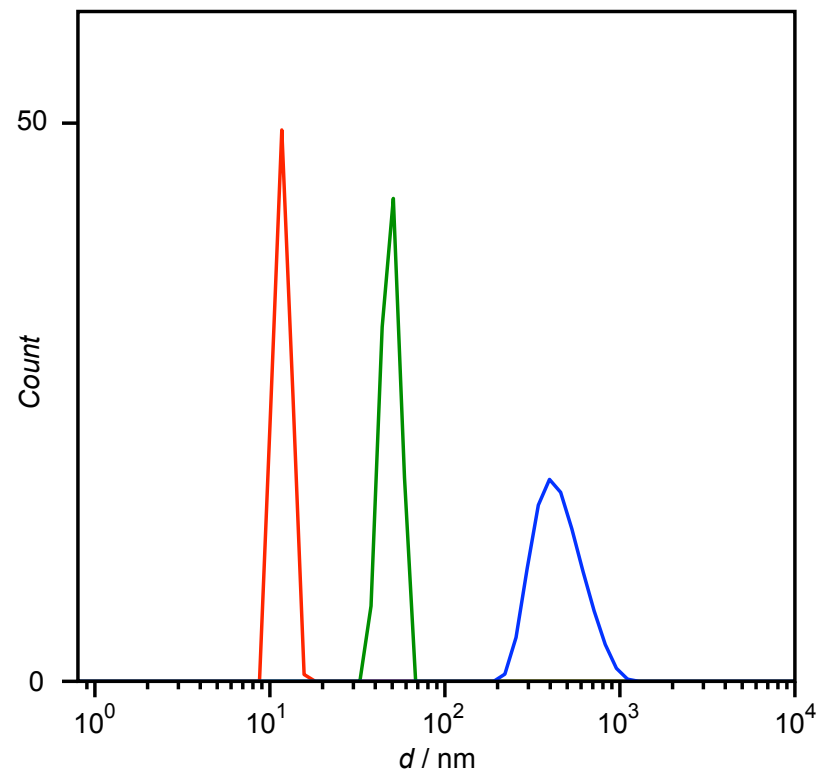

(b)

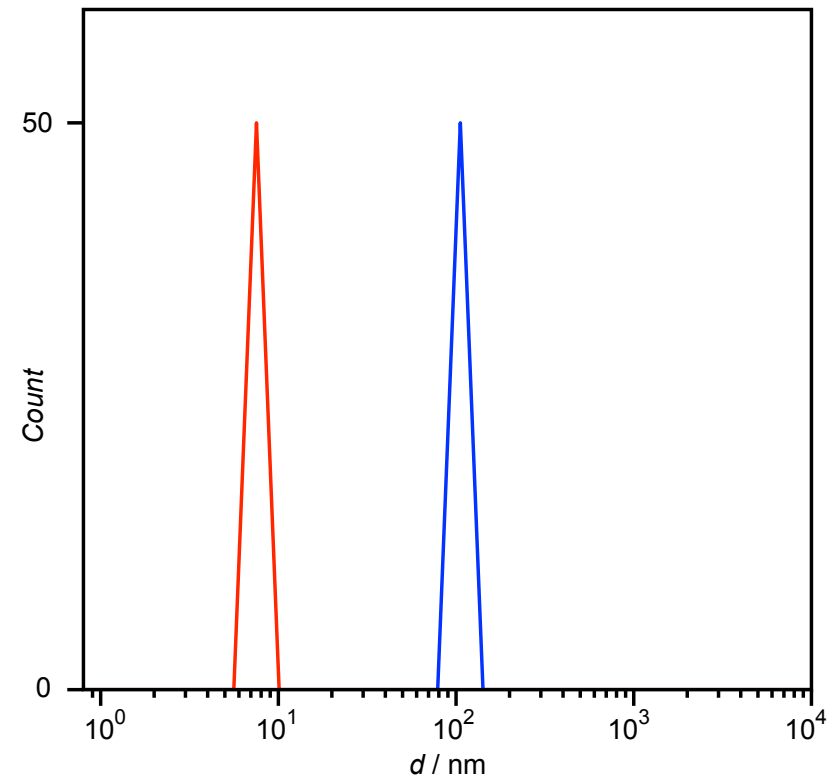

Figure S15. Hydrodynamic diameters seen in the (a) $\mathrm{MCH}$ and (b) decalin solutions of (R)-1 at (red) $50{ }^{\circ} \mathrm{C}$, (green) $27^{\circ} \mathrm{C}$, and (blue) $2{ }^{\circ} \mathrm{C}$, as inferred from dynamic light scattering experiments.

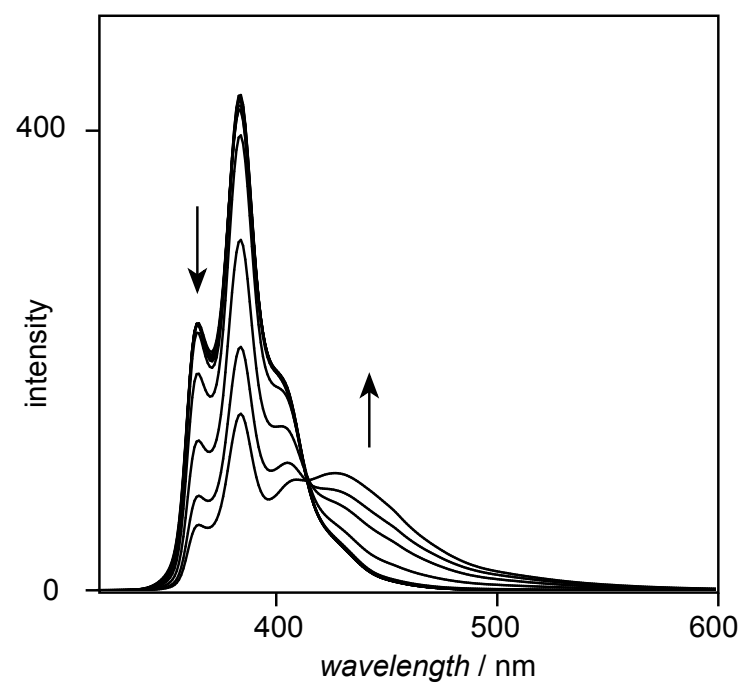

Figure S16. Temperature-dependent fluorescence spectra of $(R)-1$ in $\mathrm{MCH}$. The arrows indicate the change in the spectra as the temperature decreased from 50 to $0{ }^{\circ} \mathrm{C}$. 

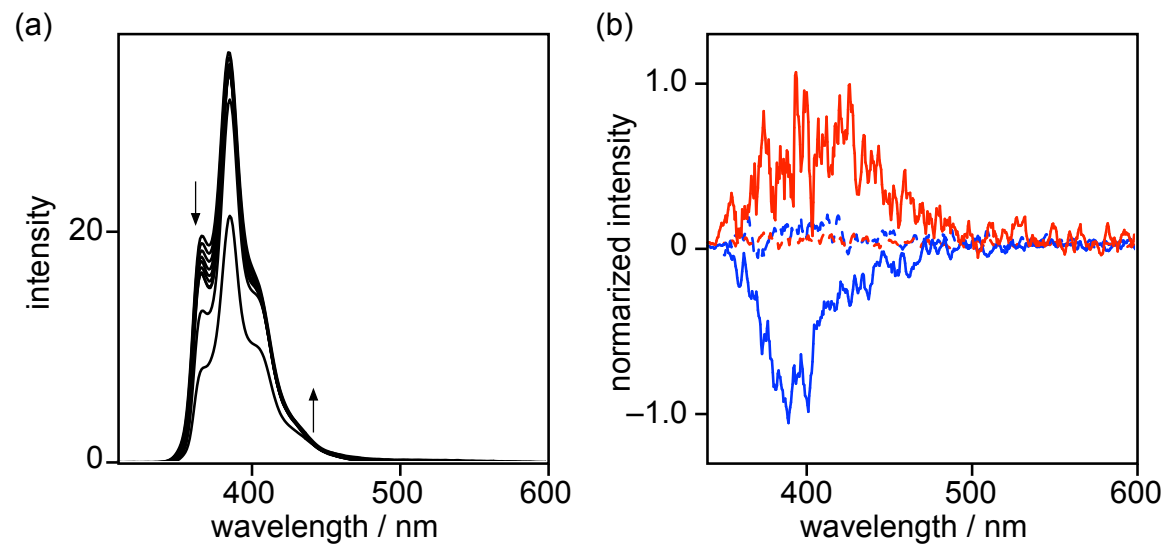

Figure S17. (a) Temperature-dependent fluorescence intensity of $(S)-1$ in decalin. The arrows indicate the change in the spectra as the temperature decreased from 50 to $0{ }^{\circ} \mathrm{C}$. (b) CPL emission of $(S)-\mathbf{1}$ (red) and (R)-1 (blue) in decalin at $0{ }^{\circ} \mathrm{C}$ (solid line) and $50{ }^{\circ} \mathrm{C}$ (dashed line). These experimental conditions are excited at $310 \mathrm{~nm}$ and $[(S)-1$ or $(R)-\mathbf{1}]=5.0 \times 10^{-5}$ $\mathrm{mol} \mathrm{L}{ }^{-1}$.

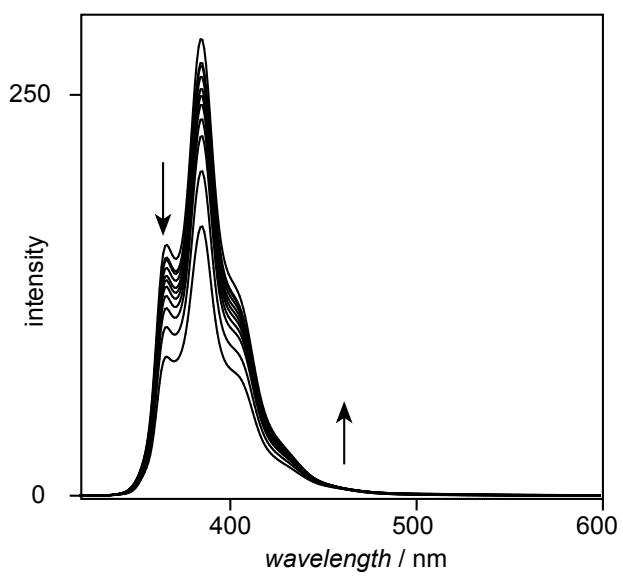

Figure S18. Temperature-dependent fluorescence spectra of $(R)-1$ in decalin. The arrows indicate the change in the spectra as the temperature decreased from 50 to $0{ }^{\circ} \mathrm{C}$. 

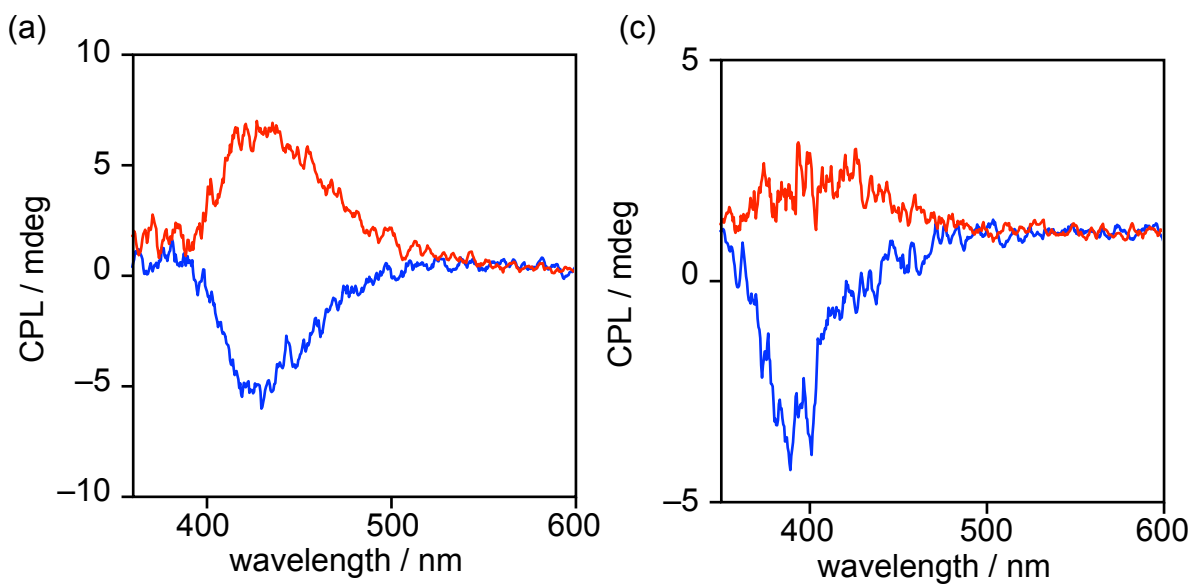

(b)

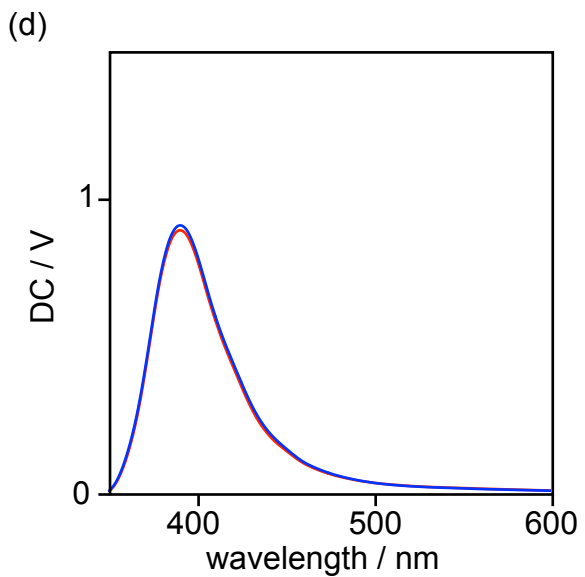

Figure S19. (a,c) CPL spectra (Y-axis: CPL intensity) and (b,d) fluorescence intensity from the DC signal of $(S)-1$ (red) and $(R)-1$ (blue) in (a,b) $\mathrm{MCH}$ and $(\mathrm{c}, \mathrm{d})$ decalin at $0{ }^{\circ} \mathrm{C}$. The spectra were recorded at a concentration of $2.0 \times 10^{-5} \mathrm{~mol} \mathrm{~L}^{-1}$ and an excitation wavelength of $310 \mathrm{~nm}$. 


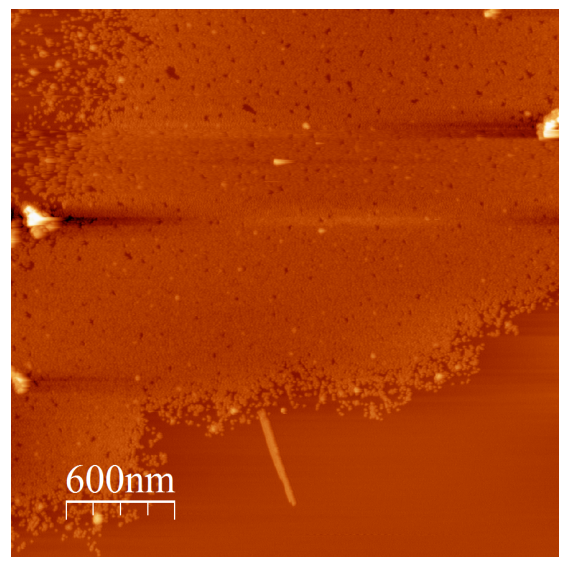

Figure S20. AFM image $(3 \mu \mathrm{m} \times 3 \mu \mathrm{m})$ of spin-coated thin films of $(S)$-1 prepared from its $\mathrm{MCH}$ solution at $50{ }^{\circ} \mathrm{C}$. $[(S)-\mathbf{1}]$ $=7.5 \times 10^{-5} \mathrm{~mol} \mathrm{~L}^{-1}$.

(a)

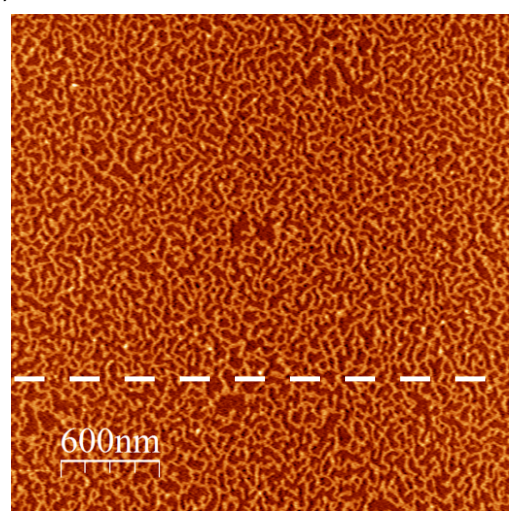

(b)

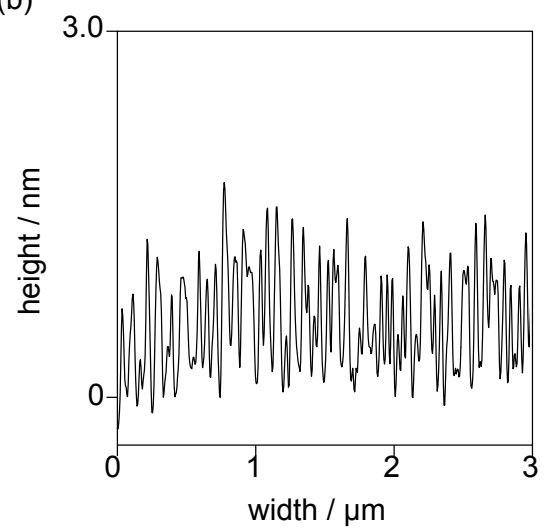

(c)

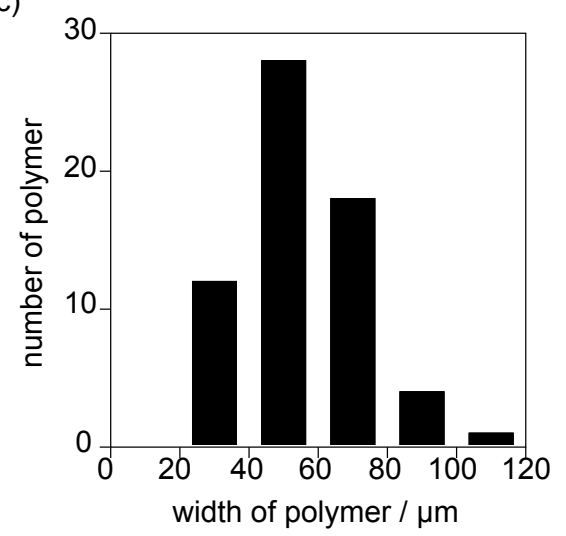

Figure S21. AFM image $(3 \mu \mathrm{m} \times 3 \mu \mathrm{m})$ of spin-coated thin films of $(S)-\mathbf{1}$ on mica prepared from its $\mathrm{MCH}$ solution at $20^{\circ} \mathrm{C}$. $[(S)-1]=7.5 \times 10^{-5} \mathrm{~mol} \mathrm{~L}^{-1}$. (b) The height profiles of the AFM image along the white dashed line in (a). (c) A histogram of the randomly picked up fiber-width from the AFM image of (a). 


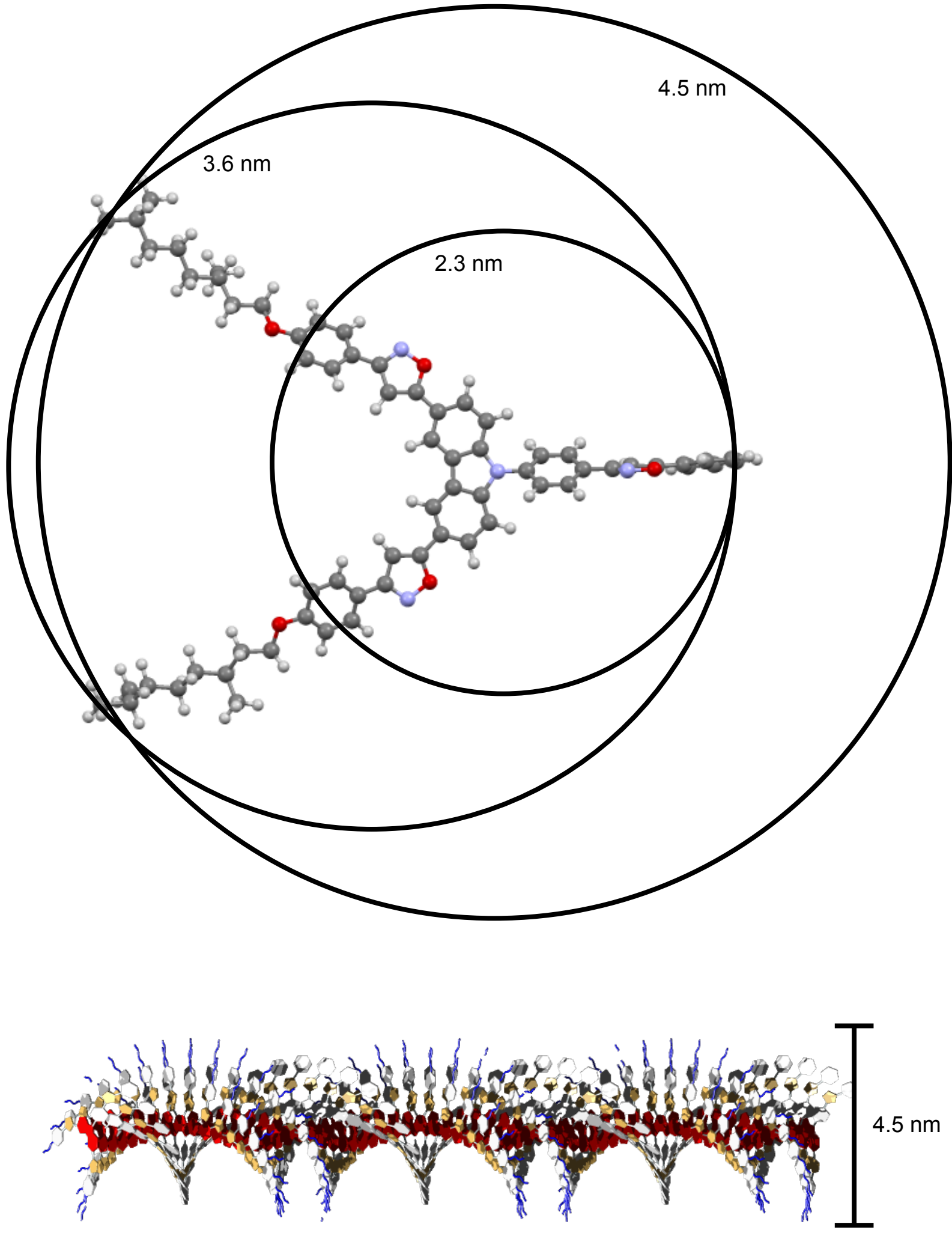

Figure S22. Molecular model of compound (S)-1. 
Table S1. Induced shift values of (S)-1 seen in the NMR spectra in chloroform- $d$.

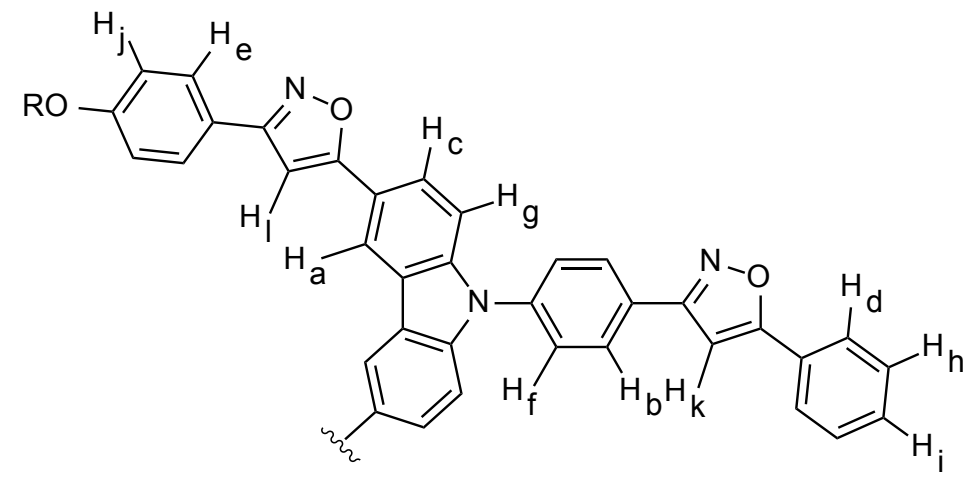

\begin{tabular}{|c|c|c|c|c|c|c|c|c|}
\hline proton & $\mathrm{a}$ & $\mathrm{b}$ & $\mathrm{c}$ & $\mathrm{e}$ & $\mathrm{f}$ & $\mathrm{j}$ & $\mathrm{k}$ & 1 \\
\hline induced shift $/ \mathrm{ppm}$ & -0.78 & -0.26 & -0.59 & -0.20 & -0.63 & -0.26 & -0.18 & -0.60 \\
\hline
\end{tabular}

Table S2. Induced shift values of $(R)-\mathbf{1}$ seen in the NMR spectra in chloroform- $d$.

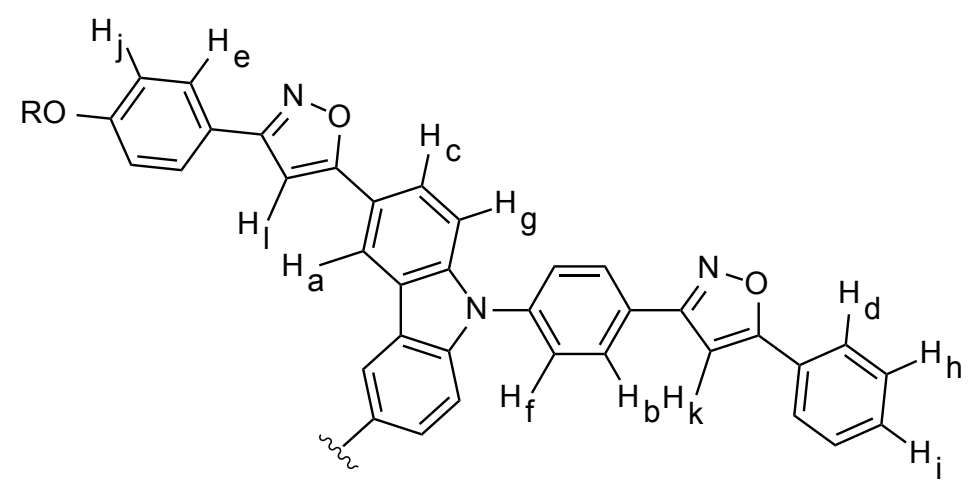

\begin{tabular}{|c|c|c|c|c|c|c|c|c|}
\hline proton & $\mathrm{a}$ & $\mathrm{b}$ & $\mathrm{c}$ & $\mathrm{e}$ & $\mathrm{f}$ & $\mathrm{j}$ & $\mathrm{k}$ & 1 \\
\hline induced shift / ppm & -0.79 & -0.25 & -0.59 & -0.20 & -0.53 & -0.38 & -0.17 & -0.60 \\
\hline
\end{tabular}


Table S3. Thermodynamic parameters of (S)-1 determined by van der Schoot's model in MCH.

\begin{tabular}{|c|c|c|c|c|c|}
\hline conc. $/ \mathrm{mol} \mathrm{L}^{-1}$ & $T_{\mathrm{e}} / \mathrm{K}$ & $K_{\mathrm{e}}\left(T_{\mathrm{e}}\right) / \mathrm{L} \mathrm{mol}^{-1}$ & $\Delta H_{\mathrm{e}} / \mathrm{kJ} \mathrm{mol}^{-1}$ & $K_{\mathrm{a}}$ & $N_{\mathrm{n}}\left(T_{\mathrm{e}}\right)$ \\
\hline $5.0 \times 10^{-5}$ & $299.9 \pm 0.2$ & $2.0 \times 10^{4}$ & $(-1.03 \pm 0.04) \times 10^{2}$ & $(0.9 \pm 0.1) \times 10^{-2}$ & $4.8 \pm 0.4$ \\
\hline $4.0 \times 10^{-5}$ & $298.2 \pm 0.2$ & $2.5 \times 10^{4}$ & $(-1.02 \pm 0.06) \times 10^{2}$ & $(1.4 \pm 0.2) \times 10^{-2}$ & $4.1 \pm 0.5$ \\
\hline $3.5 \times 10^{-5}$ & $295.6 \pm 0.2$ & $2.9 \times 10^{4}$ & $(-0.89 \pm 0.06) \times 10^{2}$ & $(1.7 \pm 0.2) \times 10^{-2}$ & $3.9 \pm 0.5$ \\
\hline $3.0 \times 10^{-5}$ & $293.7 \pm 0.1$ & $3.3 \times 10^{4}$ & $(-0.72 \pm 0.03) \times 10^{2}$ & $(1.0 \pm 0.1) \times 10^{-2}$ & $4.6 \pm 0.6$ \\
\hline
\end{tabular}

$T_{\mathrm{e}}, K_{e}\left(T_{\mathrm{e}}\right), \Delta H_{\mathrm{e}}, K_{\mathrm{a}}$, and $N_{\mathrm{n}}\left(T_{\mathrm{e}}\right)$ denote elongation temperature, association constant in the elongation process at the elongation temperature, the enthalpic gain in the elongation process, equilibrium constant between nucleation and elongation, and degree of polymerization at the elongation temperature, respectively.

Table S4. Thermodynamic parameters of $(R)$-1 determined by van der Schoot's model in MCH.

\begin{tabular}{|c|c|c|c|c|c|}
\hline conc. $/ \mathrm{mol} \mathrm{L}^{-1}$ & $T_{\mathrm{e}} / \mathrm{K}$ & $K_{\mathrm{e}}\left(T_{\mathrm{e}}\right) / \mathrm{L} \mathrm{mol}^{-1}$ & $\Delta H_{\mathrm{e}} / \mathrm{kJ} \mathrm{mol}^{-1}$ & $K_{\mathrm{a}}$ & $N_{\mathrm{n}}\left(T_{\mathrm{e}}\right)$ \\
\hline $5.0 \times 10^{-5}$ & $302.1 \pm 0.2$ & $2.0 \times 10^{4}$ & $(-1.01 \pm 0.06) \times 10^{2}$ & $(1.1 \pm 0.3) \times 10^{-2}$ & $5 \pm 1$ \\
\hline $4.0 \times 10^{-5}$ & $299.7 \pm 0.3$ & $2.5 \times 10^{4}$ & $(-0.92 \pm 0.07) \times 10^{2}$ & $(1.4 \pm 0.3) \times 10^{-2}$ & $4.1 \pm 0.9$ \\
\hline $3.5 \times 10^{-5}$ & $296.6 \pm 0.2$ & $2.9 \times 10^{4}$ & $(-1.01 \pm 0.06) \times 10^{2}$ & $(3.2 \pm 0.5) \times 10^{-2}$ & $3.2 \pm 0.5$ \\
\hline $3.0 \times 10^{-5}$ & $294.2 \pm 0.1$ & $3.3 \times 10^{4}$ & $(-0.97 \pm 0.04) \times 10^{2}$ & $(2.8 \pm 0.8) \times 10^{-2}$ & $4 \pm 1$ \\
\hline
\end{tabular}

$T_{\mathrm{e}}, K_{e}\left(T_{\mathrm{e}}\right), \Delta H_{\mathrm{e}}, K_{\mathrm{a}}$, and $N_{\mathrm{n}}\left(T_{\mathrm{e}}\right)$ denote elongation temperature, association constant in the elongation process at the elongation temperature, the enthalpic gain in the elongation process, equilibrium constant between nucleation and elongation, and degree of polymerization at the elongation temperature, respectively. 
Table S5. Cartesian coordinate of (S)-1.

Number of imaginary frequencies 0

$E$ (Total) $\quad 740.805 \mathrm{kcal} \mathrm{mol}^{-1}$

Standard orientation:

\begin{tabular}{|c|c|c|c|c|c|}
\hline \multirow{2}{*}{$\begin{array}{l}\text { Center } \\
\text { Number }\end{array}$} & \multirow{2}{*}{$\begin{array}{l}\text { Atomic } \\
\text { Number }\end{array}$} & \multirow{2}{*}{$\begin{array}{l}\text { Atomic } \\
\text { Type }\end{array}$} & \multicolumn{3}{|c|}{ Coordinates (Angstroms) } \\
\hline & & & $\mathrm{X}$ & $\mathrm{Y}$ & $\mathrm{Z}$ \\
\hline 1 & 6 & 0 & -5.202220 & 2.499935 & -0.152672 \\
\hline 2 & 1 & 0 & -6.230665 & 2.852015 & -0.196328 \\
\hline 3 & 6 & 0 & -4.141826 & 3.393400 & -0.060273 \\
\hline 4 & 1 & 0 & -4.340682 & 4.468830 & -0.015758 \\
\hline 5 & 6 & 0 & -2.797376 & 2.947993 & -0.024121 \\
\hline 6 & 6 & 0 & -2.491671 & 1.579275 & -0.087875 \\
\hline 7 & 1 & 0 & -1.458680 & 1.234030 & -0.063020 \\
\hline 8 & 6 & 0 & -3.537623 & 0.665486 & -0.181429 \\
\hline 9 & 6 & 0 & -4.897817 & 1.133284 & -0.204073 \\
\hline 10 & 6 & 0 & -4.965379 & -1.164679 & -0.351547 \\
\hline 11 & 6 & 0 & -5.351018 & -2.509482 & -0.427912 \\
\hline 12 & 1 & 0 & -6.400020 & -2.795755 & -0.462076 \\
\hline 13 & 6 & 0 & -4.345355 & -3.468410 & -0.445000 \\
\hline 14 & 1 & 0 & -4.608406 & -4.529270 & -0.505038 \\
\hline 15 & 6 & 0 & -2.976178 & -3.109161 & -0.383783 \\
\hline 16 & 6 & 0 & -2.590220 & -1.762369 & -0.293147 \\
\hline 17 & 1 & 0 & -1.538770 & -1.483410 & -0.234025 \\
\hline 18 & 6 & 0 & -3.580254 & -0.783969 & -0.274697 \\
\hline 19 & 6 & 0 & 0.090632 & 5.249396 & 0.169371 \\
\hline 20 & 6 & 0 & 1.466712 & 5.737475 & 0.131494 \\
\hline 21 & 6 & 0 & 2.427068 & 5.085483 & -0.671833 \\
\hline 22 & 1 & 0 & 2.135011 & 4.222265 & -1.271633 \\
\hline 23 & 6 & 0 & 3.737000 & 5.538605 & -0.712681 \\
\hline 24 & 1 & 0 & 4.493257 & 5.052984 & -1.325185 \\
\hline 25 & 6 & 0 & 4.093397 & 6.665882 & 0.062166 \\
\hline 26 & 6 & 0 & 3.155847 & 7.332581 & 0.863055 \\
\hline 27 & 1 & 0 & 3.425837 & 8.200091 & 1.455034 \\
\hline 28 & 6 & 0 & 1.842023 & 6.859971 & 0.887830 \\
\hline 29 & 1 & 0 & 1.096978 & 7.371778 & 1.503379 \\
\hline 30 & 6 & 0 & -1.960542 & -4.145748 & -0.412070 \\
\hline 31 & 6 & 0 & -0.593575 & -4.173512 & -0.542065 \\
\hline 32 & 1 & 0 & 0.090235 & -3.358193 & -0.652770 \\
\hline 33 & 6 & 0 & -0.226771 & -5.579978 & -0.487616 \\
\hline 34 & 6 & 0 & 1.120309 & -6.137289 & -0.577326 \\
\hline 35 & 6 & 0 & 2.132972 & -5.433904 & -1.264656 \\
\hline 36 & 1 & 0 & 1.902948 & -4.477662 & -1.736738 \\
\hline 37 & 6 & 0 & 3.415920 & -5.952650 & -1.353491 \\
\hline 38 & 1 & 0 & 4.211276 & -5.429324 & -1.879265 \\
\hline 39 & 6 & 0 & 3.691548 & -7.198678 & -0.745566 \\
\hline 40 & 6 & 0 & 2.701012 & -7.917296 & -0.061939 \\
\hline 41 & 1 & 0 & 2.909342 & -8.874595 & 0.402923 \\
\hline 42 & 6 & 0 & 1.415557 & -7.376920 & 0.013493 \\
\hline 43 & 1 & 0 & 0.629863 & -7.927153 & 0.538745 \\
\hline 44 & 6 & 0 & 5.914102 & 8.161907 & 0.681238 \\
\hline
\end{tabular}




\begin{tabular}{|c|c|c|c|c|c|}
\hline 45 & 1 & 0 & 5.752650 & 7.978906 & 1.755975 \\
\hline 46 & 1 & 0 & 5.361410 & 9.055934 & 0.347450 \\
\hline 47 & 6 & 0 & 5.408216 & -8.878676 & -0.336999 \\
\hline 48 & 1 & 0 & 4.787277 & -9.673101 & -0.782125 \\
\hline 49 & 1 & 0 & 5.268327 & -8.836567 & 0.755997 \\
\hline 50 & 6 & 0 & -7.197796 & 0.055571 & -0.353519 \\
\hline 51 & 6 & 0 & -9.989119 & 0.137085 & -0.435808 \\
\hline 52 & 6 & 0 & -11.452371 & 0.177019 & -0.474952 \\
\hline 53 & 6 & 0 & -12.349706 & 0.316433 & 0.658683 \\
\hline 54 & 1 & 0 & -12.051220 & 0.403515 & 1.683342 \\
\hline 55 & 6 & 0 & -13.615883 & 0.298044 & 0.125597 \\
\hline 56 & 6 & 0 & -14.965720 & 0.392774 & 0.655804 \\
\hline 57 & 6 & 0 & -15.181099 & 0.304753 & 2.042620 \\
\hline 58 & 1 & 0 & -14.339673 & 0.159704 & 2.719247 \\
\hline 59 & 6 & 0 & -16.478430 & 0.399838 & 2.551090 \\
\hline 60 & 1 & 0 & -16.645409 & 0.331597 & 3.625646 \\
\hline 61 & 6 & 0 & -17.562452 & 0.581070 & 1.685720 \\
\hline 62 & 1 & 0 & -18.572913 & 0.654791 & 2.086852 \\
\hline 63 & 6 & 0 & -17.350554 & 0.667056 & 0.305286 \\
\hline 64 & 1 & 0 & -18.195642 & 0.807318 & -0.368356 \\
\hline 65 & 6 & 0 & -16.057758 & 0.573551 & -0.212483 \\
\hline 66 & 1 & 0 & -15.888206 & 0.639518 & -1.289404 \\
\hline 67 & 6 & 0 & -1.722893 & 3.918889 & 0.074638 \\
\hline 68 & 6 & 0 & -0.358642 & 3.888590 & -0.079921 \\
\hline 69 & 1 & 0 & 0.274305 & 3.061210 & -0.323775 \\
\hline 70 & 7 & 0 & -5.764392 & 0.010694 & -0.307443 \\
\hline 71 & 7 & 0 & -0.975740 & 6.020552 & 0.453198 \\
\hline 72 & 7 & 0 & -1.340625 & -6.320256 & -0.333770 \\
\hline 73 & 7 & 0 & -12.177111 & 0.083345 & -1.605026 \\
\hline 74 & 8 & 0 & -2.113151 & 5.234399 & 0.406854 \\
\hline 75 & 8 & 0 & 5.413454 & 7.005014 & -0.068026 \\
\hline 76 & 8 & 0 & -2.430927 & -5.470431 & -0.280670 \\
\hline 77 & 8 & 0 & 4.993701 & -7.591145 & -0.903463 \\
\hline 78 & 8 & 0 & -13.514329 & 0.153642 & -1.276704 \\
\hline 79 & 6 & 0 & -7.883273 & -0.649781 & -1.357906 \\
\hline 80 & 1 & 0 & -7.332890 & -1.213304 & -2.112729 \\
\hline 81 & 6 & 0 & -9.276161 & -0.606673 & -1.393269 \\
\hline 82 & 1 & 0 & -9.818181 & -1.146713 & -2.175187 \\
\hline 83 & 6 & 0 & -9.292112 & 0.845491 & 0.558151 \\
\hline 84 & 1 & 0 & -9.840839 & 1.433064 & 1.296097 \\
\hline 85 & 6 & 0 & -7.899546 & 0.805389 & 0.607007 \\
\hline 86 & 1 & 0 & -7.362080 & 1.341656 & 1.390017 \\
\hline 87 & 6 & 0 & 7.389009 & 8.192172 & 0.294143 \\
\hline 88 & 1 & 0 & 7.474568 & 8.015791 & -0.799636 \\
\hline 89 & 1 & 0 & 7.920903 & 7.342108 & 0.764149 \\
\hline 90 & 6 & 0 & 8.059328 & 9.529146 & 0.673008 \\
\hline 91 & 1 & 0 & 7.466050 & 10.363087 & 0.221289 \\
\hline 92 & 6 & 0 & 9.484693 & 9.569358 & 0.080694 \\
\hline 93 & 1 & 0 & 9.465794 & 9.201003 & -0.963698 \\
\hline 94 & 1 & 0 & 10.140734 & 8.869083 & 0.631728 \\
\hline 95 & 6 & 0 & 10.083713 & 10.981773 & 0.108849 \\
\hline 96 & 1 & 0 & 10.109271 & 11.360306 & 1.149536 \\
\hline 97 & 1 & 0 & 9.429977 & 11.679413 & -0.450375 \\
\hline 98 & 6 & 0 & 11.497020 & 11.001955 & -0.487312 \\
\hline
\end{tabular}




$\begin{array}{rrrrrr}99 & 1 & 0 & 12.142877 & 10.294909 & 0.068199 \\ 100 & 1 & 0 & 11.475250 & 10.629260 & -1.528615 \\ 101 & 6 & 0 & 12.127922 & 12.410776 & -0.450443 \\ 102 & 1 & 0 & 11.987409 & 12.836440 & 0.574434 \\ 103 & 6 & 0 & 13.635109 & 12.319419 & -0.728325 \\ 104 & 1 & 0 & 14.102612 & 13.309657 & -0.707514 \\ 105 & 1 & 0 & 14.144704 & 11.701166 & 0.017734 \\ 106 & 1 & 0 & 13.839209 & 11.884521 & -1.712570 \\ 107 & 6 & 0 & 11.456878 & 13.351038 & -1.459898 \\ 108 & 1 & 0 & 11.578429 & 12.993036 & -2.487852 \\ 109 & 1 & 0 & 10.381922 & 13.439890 & -1.269881 \\ 110 & 1 & 0 & 11.884946 & 14.357628 & -1.411421 \\ 111 & 6 & 0 & 8.087347 & 9.719042 & 2.193875 \\ 112 & 1 & 0 & 7.080330 & 9.807162 & 2.612284 \\ 113 & 1 & 0 & 8.583371 & 8.882260 & 2.698270 \\ 114 & 1 & 0 & 8.634149 & 10.629669 & 2.468090 \\ 115 & 6 & 0 & 6.874184 & -8.963482 & -0.749129 \\ 116 & 1 & 0 & 7.350573 & -7.974077 & -0.579540 \\ 117 & 1 & 0 & 6.950639 & -9.135177 & -1.840580 \\ 118 & 6 & 0 & 7.631139 & -10.060607 & 0.027853 \\ 119 & 1 & 0 & 7.489109 & -9.880985 & 1.122831 \\ 120 & 6 & 0 & 9.138791 & -9.960981 & -0.290287 \\ 121 & 1 & 0 & 9.457247 & -8.900528 & -0.262651 \\ 122 & 1 & 0 & 9.327739 & -10.301814 & -1.325957 \\ 123 & 6 & 0 & 9.992869 & -10.772234 & 0.693045 \\ 124 & 1 & 0 & 9.808674 & -10.424008 & 1.728203 \\ 125 & 1 & 0 & 9.684143 & -11.835852 & 0.672658 \\ 126 & 6 & 0 & 11.486621 & -10.657378 & 0.363243 \\ 127 & 1 & 0 & 11.800386 & -9.596895 & 0.387287 \\ 128 & 1 & 0 & 11.663003 & -10.996206 & -0.675878 \\ 129 & 6 & 0 & 12.364476 & -11.483339 & 1.328282 \\ 130 & 1 & 0 & 11.926693 & -12.508869 & 1.417465 \\ 131 & 6 & 0 & 13.785492 & -11.617030 & 0.762601 \\ 132 & 1 & 0 & 14.260726 & -10.639545 & 0.627743 \\ 133 & 1 & 0 & 14.425832 & -12.199795 & 1.433350 \\ 134 & 1 & 0 & 13.785460 & -12.120813 & -0.209394 \\ 135 & 6 & 0 & 12.405484 & -10.852690 & 2.726159 \\ 136 & 1 & 0 & 12.844042 & -9.849315 & 2.703743 \\ 137 & 1 & 0 & 11.400922 & -10.760784 & 3.152677 \\ 138 & 1 & 0 & 13.003599 & -11.455681 & 3.417155 \\ 139 & 6 & 0 & 7.085313 & -11.451976 & -0.312678 \\ 140 & 1 & 0 & 6.047888 & -11.573850 & 0.012664 \\ 141 & 1 & 0 & 7.119363 & -11.648759 & -1.390121 \\ 142 & 1 & 0 & 7.673947 & -12.237838 & 0.176516\end{array}$

